\section{Who knows the rationale of the refilling time measured by plethysmography?}

\author{
Claude Franceschi \\ Centre de soins Marie Thérèse, Paris, \\ France
}

\begin{abstract}
This mini-review analyzes the pathophysiology significance of the refilling time (RT) assessed in limbs after exercise by the means of plethysmographic techniques. Based on such a rationale the Author offers an interpretation of RT following suppression of reflux points respectively achieved by CHIVA or by ablative techniques, showing the pathophysiologic differences between two different and controversial strategies of managing chronic venous insufficiency.
\end{abstract}

\section{Pathophysiology significance of the refilling time}

Let's analyze the rationale of the refilling time (RT) in order to understand the related hemodynamics basis, as well as field and borders of interest in the venous insufficiency assessment.

Normally, the leg elevation as well as the calf pumping exhausts the calf blood volume accumulated by the standing or sitting still posture. Reclining down the leg or pumping stop reverses the pressure gradient but not the flow because it closes the valves. The valves open again when the refilling of the venous bed is achieved. The normal plethysmographic RT by calf pumping measured at the end of several free foot flexions and dorsi-flexions ranges between 18 and $>20$ seconds. The venous bed is quicker refilled and consequently the RT time is shortened by the reflux due to the deep and/or superficial valve incompetence (Figure 1). Furthermore, RT is also proportional to the volume reduction achieved by the previous calf pumping or leg elevation. This reduction is obtained at maximum during the elevation while it depends on the pump efficiency during the calf activation. So, due to the difference of volume reduction, the expected RT will be longer after elevation than after calf activation. The calf pump efficiency can be impaired by several reasons, as valve incompetence, venous obstacles, and defect of muscle volume, strength or mobility.
According to Cestmir Recek's the strain gauge measurements improved the plethysmographic parameters as follows:

After great saphenous vein (GSV) crossectomy, the mean of 30 measurements was: refill time t-90 by $24.5 \mathrm{~s}$; t-50 by 10.6 $\mathrm{s}$; refill volume by $0.94 \mathrm{~mL} / 100 \mathrm{~mL}$ (a mean of 30 measurements). ${ }^{1}$

After crossectomy and stripping, the mean of 18 measurements was: refill time t90 by $26.2 \mathrm{~s}$; t- 50 by $10.8 \mathrm{~s}$; refill volume by $1.1 \mathrm{~mL} / 100 \mathrm{~mL} .^{2}$

The Recek's conclusion was: the differences were minimal and the postoperative results both after high ligation and after high ligation plus stripping were well in the range of normal values.

The hemodynamic analysis of these results shows limitations and sometimes misinterpretations of the data.

Indeed, though very minimal in terms of figures, the RT difference after crossectomy alone and crossectomy + stripping is very relevant in terms of pathophysiology and paradoxically not in favor of the supposed best result, i.e after stripping.

In fact, the improved RT reflects not only the overloading reflux volume abolition, but it also inevitably reflects the impairment of the physiologic superficial flow caused by stripping or any endovenous destructive procedure.

In case of sapheno-femoral junction (SFJ) and GSV total incompetence, the refilling time is shortened by the huge spill from the femoral vein (N1 network) into N1 again but below the knee via the GSV (N2 network) then. This represents a typical closed shunts $(\mathrm{N} 1>\mathrm{N} 2>\mathrm{N} 1)$.

The GSV closed shunt disconnection at the SFJ eliminates N1 flow, and leaves behind $\mathrm{N} 2$ flow only, which achieves a normal range $\mathrm{RT}^{1}$ despite a still reversed GSV flow. As a matter of fact, the physiological drainage hierarchy is restored $(\mathrm{N} 2>\mathrm{N} 1$ instead of $\mathrm{N} 1>\mathrm{N} 2>\mathrm{N} 1$ ). Yet, the RT normalization does not take account of a still too high foot-groin hydrostatic pressure though shorter than the previous foot-heart height. Stripping or saphenous endovenous ablation not only suppress the foot-groin column but increases RT even more because the whole GSV physiological flow is also ablated. This explains the slightly longer refilling time after stripping ${ }^{2}$ i.e after ablation of most of the N2 volume flow. This last plethysmographic improvement reflects in fact superficial drainage impairment. As a matter of fact, stripping or any other endo venous superficial ablative techniques impair the skin drainage, which is responsible for reactive neo-angiogenesis, matting, telangiectasias and varicose recurrence. That is why RT interpretation following sur-
Correspondence: Claude Franceschi, Centre de soins Marie Thérèse, Paris, France.

E-mail: claude.franceschi@gmail.com

Key words: Plethysmography; venous pathophysiology; chronic venous insufficiency; CHIVA; saphenous ablation; lower limb drainage.

This work is licensed under a Creative Commons Attribution 4.0 License (by-nc 4.0).

(C) Copyright C. Franceschi, 2018

Licensee PAGEPress, Italy

Veins and Lymphatics 2018; 7:7199

doi:10.4081/vl.2018.7199

gery does not take into account all the aspects of the venous insufficiency, particularly the hydrostatic pressure and the drainage impairment. That is why in case of SFJ and total GSV trunk incompetence (N2) the column should be segmented twice, at the groin and below the knee (flush below a leg re-entry perforator). Most of the time, the GSV trunk is incompetent at the thigh but competent below the knee and the reflux reaches the ankle or the foot through an incompetent tributary (N3). In that case, if there is an interposed re-entry perforator on the GSV trunk, the second hydrostatic column segmentation is performed flush the $\mathrm{N} 2>\mathrm{N} 3$ escape point, and stops at the same time the shunt II overload N2>N3.

In SHUNT III, there is no available interposed re-entry on the N2 trunk. Then, the $\mathrm{N} 2>\mathrm{N} 3$ flush ligation is a first step of the CHIVA 2 steps strategy. The one step strategy is possible. It consists of both $\mathrm{N} 1>\mathrm{N} 2$ and $\mathrm{N} 2>\mathrm{N} 3$ flush ligation combined with a N2 devalvulation down to a re-entry perforator.

This CHIVA strategy segments the superficial network in two distinct drained territories (thigh and leg). Consequently, RT at the leg is improved, even if not as much after stripping but for a better functional result and less recurrence. ${ }^{3-9}$

So the refilling time is fortunately increased up to the normal range but less than after stripping or endo-venous ablative procedures. Furthermore, the concept of reflux should be revisited. Indeed, the normal refilling time restore after crossectomy or CHIVA crossotomy despite a still reversed flow (reflux) demonstrates that the reflux after CHIVA is not pathogenic flow because it is no more overloaded and drains the tissues according to the physiological hierarchy $\mathrm{N} 3>\mathrm{N} 2>\mathrm{N} 1$ or $\mathrm{N} 3>\mathrm{N} 1$.

Finally, as reported in one of the first prospective randomised study ${ }^{10}$ comparing CHIVA with compression in the treatment 


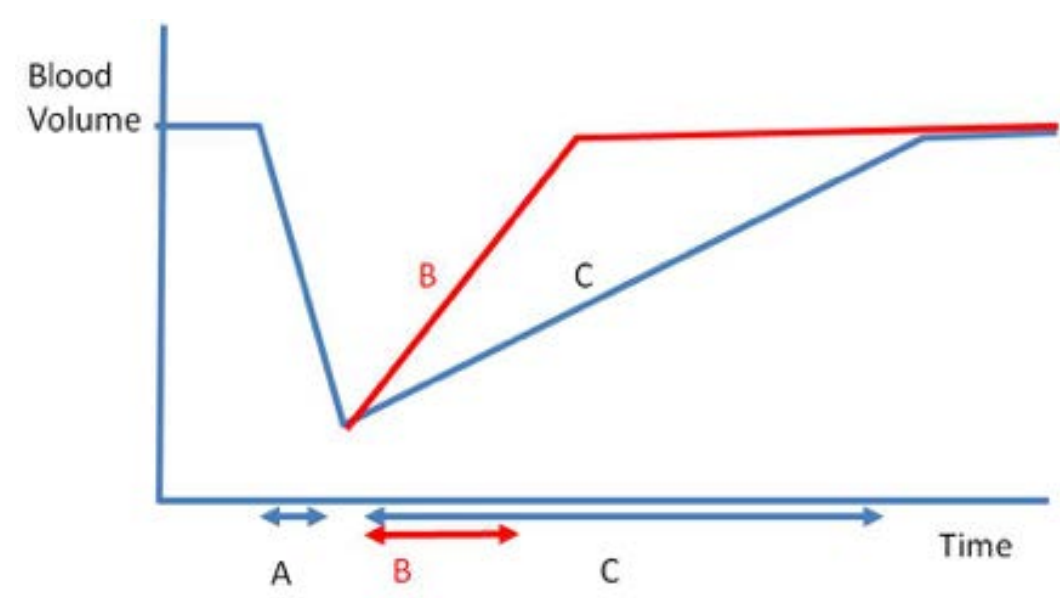

Figure 1. In case of venous incompetence, the diastolic refilling time will be quicker, less than 20 seconds, fed by the venous reflux, in proportion to the valve incompetence rate. A: Emptying volume and time. B: Refilling volume and time in case of venous incompetence: capillary ouflow + Relux flow. C: Refilling volume and time normal venous competence: capillary ouflow.

of venous ulceration, the surgical group showed a sifnificant improvement of all plethysmographic parameters except of ejection fraction, at 6 months. However, the reverse direction of the flow is not responsible for inflammation but just its amount. ${ }^{11,12}$

\section{References}

1. Recek C, Karisch E, Gruber J. Veränderungen der Perforansvenen und tiefen Unterschenkelvenen nach Beseitigung des Saphena-Refluxes. Phlebologie 2000;29:37-40.
2. Recek C. Saphena-Reflux als Ursache der venösen Zirkulationsstörung bei primärer Varikose mit chronischer Veneninsuffizienz. Acta Chir Austriaca 1998.

3. Franceschi C, Cappelli M, Ermini S, et al. CHIVA: hemodynamic concept, strategy and results. Int Angiol 2016;35:8-30.

4. Pares JO, Juan J, Tellez R, et al. Varicose vein surgery: stripping versus the CHIVA method: a randomized controlled trial. Ann Surg 2010;251:62431.

5. Carandina S, Mari C, De Palma M, et al. Varicose vein stripping vs haemody namic correction (CHIVA): a long term randomised trial. Eur J Vasc Endovasc Surg 2008;35:230-7.

6. Bellmunt-Montoya S, Escribano JM, Dilme J, Martinez-Zapata MJ. CHIVA methodfor the treatment of chronic venous insufficiency. Cochrane database Syst Rev 2013;7:CD009648.

7. Chan C-Y, Chen T-C, Hsieh Y-K, Huang J-H. Retrospective comparison of clinical outcomes between endovenous laser and saphenous vein-sparing surgery for treatment of varicose veins. World J Surg 2011;35:1679-86.

8. Wang H, Chen Q, Fei Z, et al. Hemodynamic classification and CHIVA treatment of varicose veins in lower extremities (VVLE). Int J Clin Exp Med 2016;9:2465-71.

9. Mendoza E. Primum non nocere. Veins and Lymphatics 2017;6:6646.

10. Zamboni P, Cisno C, Marchetti F, et al. Minimally invasive surgical management of primary venous ulcers vs. compression treatment: a randomized clinical trial. Eur J Vasc Endovasc Surg 2003;25:313-8. Erratum in: Eur J Vasc Endovasc Surg 2003;26:337-8.

11. Tisato V, Zauli G, Gianesini S, et al. Modulation of circulating cytokinechemokine profile in patients affected by chronic venous insufficiency undergoing surgical hemodynamic correction. J Immunol Res 2014;2014: 473765 .

12. Zamboni P, Spath $\mathrm{P}$, Tisato V, et al. Oscillatory flow suppression improves inflammation in chronic venous disease. J Surg Res 2016;205:238-45. 